\title{
Redes e capital social: o enfoque da informação para o desenvolvimento local
}

\author{
Regina Maria Marteleto \\ Professora doutora da Escola de Ciência da \\ Informação (ECI) da UFMG. \\ E-mail: reginamar@eci.ufmg.br \\ Antonio Braz de Oliveira e Silva \\ Doutorando em ciência da informação da ECI/ \\ UFMG e analista do IBGE. \\ E-mail: antonio_braz@uol.com.br
}

\begin{abstract}
Resumo
O acesso à informação é um elemento-chave para o desenvolvimento econômico e social de comunidades e grupos sociais. A capacidade de obter informações, além dos contornos restritos da própria comunidade, é parte do capital relacional dos indivíduos e grupos. As transformações dependem das redes existentes entre os indivíduos do grupo e atores localizados em outros espaços sociais, ou seja, do capital social da comunidade. Por ser tratado como capital, da mesma forma que o capital humano ou financeiro, investimentos para sua ampliação devem permitir retornos ou benefícios, servindo de base para o desenvolvimento, o que tem sido amplamente pesquisado. O uso da metodologia de análise de redes sociais vem se difundindo rapidamente, nos últimos anos, trazendo contribuições significativas para a compreensão do papel do capital social no desenvolvimento. A construção de redes sociais e a conseqüente aquisição de capital social estão condicionadas por fatores culturais, políticos e sociais. O próprio conceito de capital social é multidimensional, o que signitica incorporar vários niveis e unidades de análise. A combinação da metodologia de análise de redes com uma base teórica sólida amplia os espaços de pesquisa, em um espectro que vai das pesquisas sobre o acesso às informações básicas sobre saúde pública em comunidades urbanas ao comércio internacional, passando pela análise do desenvolvimento regional, através do estudo dos arranjos produtivos locais.
\end{abstract}

Palavras-chave

Informação; Redes sociais; Capital social; Arranjos produtivos locais; Desenvolvimento local; Desenvolvimento comunitário.

\section{Networks and social capital: the role of information in local development}

\begin{abstract}
Access to information plays a key role in economic and social development of communities and groups. The ability of gathering information beyond the frontiers of the community is part of the relational capital of individuals and social groups. It means that any transformation depends on existing networks between individuals of the community and others belonging to other social groups - the social capital of the community. It means that, like any other capital (human, financial), investment in social capital also has a return or benefit. The analytical framework of social networks brings forth significant understanding about the role of social capital in a development process. Social networks and social capital depend on cultural, political and social factors. Social capital is a multidimensional concept, which takes into account many units and analytical levels. The combination of social network analysis and a strong conceptual framework may broaden the research field, ranging from access to basic information on public health in urban communities to international trade and to regional development, using the studies of local industrial networks (clusters).
\end{abstract}

Keywords

Information; Social networks; Social capital; Local industrial networks (cluster); Local development.

\section{INTRODUÇÃO}

Nesse artigo pretende-se enfatizar a importância do uso da metodologia de análise de redes sociais para a compreensão do fenômeno do acesso à informação e sua importância para o desenvolvimento econômico e social de comunidades e grupos sociais. A informação como base para a geração do conhecimento e ação social e sua relevância econômica e política têm sido investigadas em várias áreas do conhecimento, tais como a ciência da informação, a sociologia, a economia e a ciência política. O uso da metodologia de análise de redes nesses estudos vem se ampliando nos últimos anos, e, embora haja importante discussão epistemológica sobre a sua posição na pesquisa científica, é inegável que cria uma zona de conhecimento comum entre as áreas mencionadas, especialmente pela utilização de termos com significados bem precisos. Com o objetivo de enfatizar esses aspectos, o artigo trata da análise de redes sociais, sua evolução recente e conceitos básicos, para depois analisar a idéia de que as relações existentes entre os indivíduos fazem parte do capital existente nas sociedades, enfatizando o fato de que, como capital, serve de base para o desenvolvimento social e econômico. As contribuições teóricas mais relevantes são destacadas, assim como o seu potencial de análise, sem perder de vista que não se pode usar essa, ou qualquer outra metodologia, como panacéia para toda investigação e intervenção social.

\section{A ANÁLISE DE REDES SOCIAIS}

A análise de redes sociais interessa a pesquisadores de vários campos do conhecimento que, na tentativa de compreenderem o seu impacto sobre a vida social, deram origem a diversas metodologias de análise que têm como base as relações entre os indivíduos, em uma estrutura em forma de redes. As redes são sistemas compostos por "nós" e conexões entre eles que, nas ciências sociais, são representados por sujeitos sociais (indivíduos, grupos, organizações etc.) conectados por algum tipo de relação. De forma genérica, pode-se estudar o sistema visando apenas a entender como ele se comporta e como as conexões influenciam esse comportamento, com aplicações na área de saúde pública (estudos epidemiológicos), de tecnologia da informação (a mesma idéia para os vírus de computador), sociologia (os movimentos sociais), economia (mercados e economias de rede) e matemática aplicada (otimização de algoritmos) (Watts, 1999). 
A idéia que as relações sociais compõem um tecido que condiciona a ação dos indivíduos nele inseridos é do início do século XX. A metáfora do tecido ou rede, inicialmente na sociologia e depois na psicologia e antropologia, para associar o comportamento individual à estrutura à qual ele pertence, transforma-se em uma metodologia denominada sociometria, cujo instrumento de análise apresenta-se na forma de um sociograma, isto é, diagramas de redes que permitem a visualização da estrutura que está sendo estudada.

Havia clara limitação quanto à metodologia e à ferramenta de análise. Os sociólogos, os principais utilizadores dessa técnica, estudavam grupos pequenos, em geral não formalizados. Como em análises desse tipo o número de conexões possíveis cresce exponencialmente com o aumento no número de indivíduos estudados (o número de conexões entre $\mathbf{n}$ indivíduos é $\mathbf{n}(\mathbf{n}-\mathbf{1}) / 2$ ), e não havia instrumentos, ferramentas e métodos automatizados para análise de redes, o tamanho dos grupos estudados era, necessariamente, reduzido. Assim, o método para o estudo sistemático das redes é bastante recente, datando dos anos 40, quando as relações passaram a ser representadas na forma matricial (matrizes com $\mathbf{n}$ linhas e colunas, sendo $\mathbf{n}$ o número de indivíduos, cujas células eram preenchidas com 0 e 1 , representando a ausência ou presença de relação entre dois indivíduos quaisquer), beneficiando-se da base matemática da álgebra linear. Nos anos 70, desenvolveram-se as análises mais sofisticadas e de maior porte, com o aumento da capacidade dos computadores e o desenvolvimento de softwares adequados para tratamento de grandes bases de dados e sua análise na forma de redes.

Assim, o intervalo de tempo transcorrido entre a definição teórica e conceitual da importância das redes para compreender a sociedade e o instrumental de análise que facilitasse e disseminasse os estudos empíricos, nas diversas áreas do conhecimento envolvidas, foi relativamente curto e beneficiou-se dos avanços tecnológicos na computação, no desenvolvimento de softwares e na matemática aplicada.

Existe uma discussão epistemológica em torno da análise de redes sociais. Para muitos autores, trata-se de uma metodologia de análise de dados relacionais que permite a captação de diversos fenômenos sociais que se deseja estudar, segundo a teorização de uma área de conhecimento específica; para outros, trata-se de um novo paradigma de análise estrutural (Degenne e Forsé, 1994, que utilizam o termo "interacionismo estrutural"). Para outros, é uma tentativa de se introduzir um nível intermediário entre os enfoques micro e o macro na análise da realidade social, ou entre o indivíduo e a estrutura, nas principais correntes da sociologia (Marteleto, 2001). De qualquer forma, há uma linguagem comum e métodos de coleta e análise de dados que podem ser utilizados em vários modelos teóricos. Embora seja evidente o interesse das ciências sociais pelo tema, especialmente na sociologia, suas aplicações não estão restritas a essa área.

\section{CONCEITOS BÁSICOS DA ANÁLISE DE REDES SOCIAIS}

Muitos autores destacam a importância das relações sociais dos indivíduos como um elemento-chave para a compreensão da sociedade, como, por exemplo, Norbert Elias. Sua visão foi construída a partir da crítica ao que ele denominou "as duas formas radicais da sociologia", que ora privilegiam o indivíduo, ora a estrutura. Seu trabalho foi se desenvolvendo a partir da década de 1930, quando publicou o texto denominado "A sociedade dos indivíduos", que aparece como o primeiro capítulo do livro do mesmo nome, criticando tanto o conceito de indivíduo (ser humano singular como se fora uma entidade vivendo em completo isolamento) quanto o de sociedade, muitas vezes entendida ou como um simples somatório de indivíduos ou como um objeto que existe para além dos indivíduos e que não é passível de maiores explicações.

Daí o conceito de "sociedade dos indivíduos"*, duas palavras que correntemente não são usadas dessa forma, para justificar a necessidade intelectual de entender o relacionamento entre o indivíduo e a sociedade. Assim:

O que nos falta.[...] são modelos conceituais e uma visão global mediante os quais possamos tornar compreensível no pensamento aquilo que vivenciamos diariamente na realidade, mediante os quais possamos compreender de que modo um grande número de indivíduos compõe entre si algo maior e diferente de uma coleção de indivíduos isolados: como aqueles formam uma sociedade e como sucede essa sociedade poder modificar-se de maneiras específicas, ter uma história que segue um curso não pretendido ou planejado por qualquer dos indivíduos que a compõem (Elias, 1994, p.16).

A questão subjacente é que o todo é diferente das partes que o compõem, e as leis que governam o todo não podem ser compreendidas a partir de análise dos seus elementos isolados. Para que haja verdadeira compreensão dos fenômenos sociais, é necessário que se rompa com o

\footnotetext{
"Trata-se de algo incomum de se falar, uma vez que a sociedade é composta de indivíduos, e esses existem em sociedade, mas como, na visão do autor, existe um abismo entre as noções de indivíduo e de sociedade, justifica-se essa forma de utilização como uma figura de linguagem.
} 
Redes e capital social: o enfoque da informação para o desenvolvimento local

antagonismo dos dois conceitos ou das duas interpretações. As pessoas vivem em redes de dependência, difíceis de serem rompidas. Essas redes são diferentes em cada sociedade. O modo como o indivíduo se comporta é determinado por suas relações passadas ou atuais com as outras pessoas. E a interdependência das funções humanas sujeita e molda, de forma profunda, o indivíduo.

As redes humanas têm uma ordem e leis diferentes daquelas planejadas e desejadas pelos indivíduos que a compõem. Pelo fato de os seres humanos não estarem tão presos, como outros animais, às determinações biológicas, é que o entrelaçamento das suas atividades dá origem a essas leis e estruturas de um tipo especial. Por essa razão, as redes têm mecanismos automáticos de mudança e transformações históricas que independem da vontade dos seus componentes tomados isoladamente, mas estas não são caóticas, e sim sociais.

\section{GRANOVETTER E A FORÇA DOS LAÇOS FRACOS}

Em um artigo seminal sobre a análise das redes sociais e sua importância para a compreensão das interações entre os níveis micro e macro, Granovetter (1973) coloca essa unidade de análise - as redes interpessoais - como um elemento fundamental nessa ponte. Ele analisa os laços sociais existentes, classificando-os como fortes (definidos como aqueles nos quais os indivíduos despendem mais tempo, intensidade emocional e trocas; por exemplo, a amizade) e fracos (aqueles nos quais o investimento é menor ou nulo, como, por exemplo, os mantidos com pessoas conhecidas). A partir da análise de tríades (relações entre três indivíduos, isto é, se existem as relações fortes $A B$ e $A C$, então existe a relação $B C$ ) e das pontes (ligações entre dois indivíduos situados em agrupamentos distintos e não conectados, a não ser por essa ligação que se torna a ponte entre os dois grupamentos), ele aprofunda a análise na direção de que são as relações fracas que importam para a expansão e força das redes. Intuitivamente, a explicação é simples: se dois indivíduos têm relações fortes, é provável que haja uma superposição em suas relações, e a rede, como um todo, é relativamente limitada. Assim, são as relações fracas que ampliam os limites das redes, conectando grupos que não têm ligações entre si. Introduzindo outros conceitos de rede e pesquisas empíricas, ele analisa a velocidade da informação e a importância das figuras (nós) centrais e marginais na rede para a introdução de inovações, obtenção de informações sobre emprego, do papel das lideranças em determinadas comunidades, enfatizando que a existência de laços fracos é fundamental para que esses indivíduos atinjam mais pessoas sem que haja perda de confiança.
De acordo com Hanneman, a análise de redes sociais é mais um ramo da sociologia matemática* do que uma análise estatística ou quantitativa. Enquanto os estudiosos da primeira tratam os dados como determinísticos, os da segunda os tratam como uma distribuição de probabilidade, que podem ser obtidos, de forma consistente, com a repetição dos experimentos para a obtenção dos resultados. A idéia básica de uma rede é simples: um conjunto de atores (ou nós, pontos ou agentes) entre os quais existem vínculos (ou relações). Pode haver muitos ou poucos atores e pode existir uma ou mais classes de relações entre eles. De maneira geral, para se entender bem a rede, deve-se conhecer as relações entre cada par de atores da população estudada. O uso de técnicas matemáticas (matrizes e grafos, por exemplo) permite uma descrição mais adequada e concisa de suas características. Além disso, essas técnicas permitem o uso de computadores na análise da informação e a indicação de relações não previstas, abrindo a possibilidade de novas perguntas de investigação. Portanto, o que torna cientificamente relevantes os resultados obtidos com o uso da análise de redes são as teorias das áreas de conhecimento que dão origem à pesquisa.

\section{REDES E CAPITAL SOCIAL}

O interesse pelos estudos de redes sociais está também relacionado com o aumento dos estudos na área de economia e sociologia sobre a importância do capital social. Sucintamente, a participação em redes está associada ao capital social estrutural, sendo muito relevante a compreensão do tipo de rede que se está observando (diversidade dos participantes, institucionalização de normas de decisão, objetivos gerais ou específicos, tamanho e área geográfica etc.). O nível de confiança (e expectativa) entre os indivíduos da rede está relacionado com o capital social cognitivo e influencia a ação coletiva do grupo. Em parte, relaciona-se com o acesso à informação tanto no nível local quanto mais geral, este último associado aos meios de comunicação, ou, em outros termos, às fontes pessoais e impessoais.

O capital social não deve ser confundido com o capital humano, nem com infra-estrutura. $\mathrm{O}$ capital humano

\footnotetext{
*Embora haja uma seção da Sociedade Americana de Sociologia dedicada à sociologia matemática (American Sociological Association's Section for Mathematical Sociology, http://www.sscnet.ucla.edu/soc/groups/ mathsoc/mathsoc.htm), não há consenso, mesmo nessa seção, com relação à definição desse campo de conhecimento (no próprio site, há a seguinte informação: What is Mathematical Sociology? We do not have a good definition yet.). De forma geral, o interesse é pela aplicação de modelos matemáticos nas ciências sociais, simulações por computador e desenvolvimento de programas e redes sociais. $\mathrm{O}$ que se destaca nas afirmação é que a utilização de redes nos estudos dos problemas sociais está fudamentalmente relacionada com o problema estudado e que a escolha dos sujeitos socias não segue os métodos estatísticas tradicionais.
} 
engloba as habilidades e conhecimentos dos indivíduos que, em conjunto com outras características pessoais e o esforço despendido, aumentam as possibilidades de produção e de bem-estar pessoal, social e econômico. Parte desse capital está associada ao processo, formal ou informal, de aprendizagem pelo qual todos passam, mas tanto a sua aquisição quanto o seu uso são processos afetos ao indivíduo. A infra-estrutura refere-se ao conjunto fundamental de instalações e meios para que a produção se realize e se distribua.

O capital social, por suas vez, é definido como as normas, valores, instituições e relacionamentos compartilhados que permitem a cooperação dentro ou entre os diferentes grupos sociais. Dessa forma, são dependentes da interação entre, pelo menos, dois indivíduos. Assim, fica evidente a estrutura de redes por trás do conceito de capital social, que passa a ser definido como um recurso da comunidade construído pelas suas redes de relações. A construção de redes sociais e a conseqüente aquisição de capital social estão condicionadas por fatores culturais, políticos e sociais. Entender sua constituição pode levar à sua utilização, como mais um recurso, em favor do desenvolvimento e da inclusão social, especialmente das comunidades. Para isso, deve-se ter em conta que as redes se constituem em canais pelos quais passam informação e conhecimento. Os valores e as expectativas em torno da rede dão origem a normas de controle sobre seus membros (The National Economic and Social Forum, 2003).

O capital social possui uma natureza multidimensional. A visão mais estreita o define como um conjunto de normas e redes sociais que afetam o bem-estar da comunidade na qual estão inscritas, facilitando a cooperação entre os seus membros pela diminuição do custo de se obter e processar informação. Nesse caso, as relações de base para a formação das redes seriam entre iguais, isto é, entre indivíduos similares do ponto de vista de suas características demográficas (bonding social capital ou "capital social de ligação").

No entanto, as redes assim constituídas não permitem que a comunidade rompa suas próprias fronteiras, embora essa ruptura seja fundamental para a construção de metas comuns e confiança entre seus membros. Dessa forma, as redes devem se ampliar para criar ligações com outras comunidades semelhantes e assim ampliar o alcance de suas ações (bridging social capital ou "capital social de ponte").

Embora ampliada em termos de comunidades, essa rede ainda possui características horizontais. Assim, para se entender o seu alcance, deve-se identificar laços com indivíduos que estejam em posição de autoridade, isto é, que podem intermediar recursos adicionais para o desenvolvimento da comunidade (linking social capital ou "capital social de conexão").

Observe-se que, entre o capital social de ligação e o de ponte, estão os conceitos mencionados de "laços fortes e fracos”, conforme assinalado por Granovetter (1973). Na verdade, a utilização do conceito de ligação do tipo ponte para assinalar a relação entre grupos distintos já aparecia nesse trabalho, para exemplificar que as relações fracas existentes entre grupos distintos seriam fundamentais para criar redes que ampliassem o alcance de algumas informações, como, por exemplo, sobre oportunidades de emprego. Os laços fortes (no caso, dentro de uma mesma comunidade) não cumpririam essa função, dado que há uma sobreposição entre as redes de cada indivíduo (as informações sobre emprego seriam as mesmas). Para as comunidades, a situação ideal é ter o seu capital social dividido entre essas três formas de redes sociais, uma vez que cada uma delas responde por aspectos importantes para o sucesso da comunidade: i) confiança e comprometimento; ii) ampliação das fontes de informações e conhecimento; iii) acesso às instituições e ao poder.

\section{A BASE TEÓRICA E A CONTRIBUIÇÃO DE PIERRE BOURDIEU}

Na maior parte dos estudos sobre o tema, destacam-se três teóricos ligados ao conceito de capital social (Durston, 2002): James Coleman, que aplica o conceito na área da educação e analisa o seu papel no crescimento do capital humano, em uma abordagem baseada na escolha racional. Para este autor, o capital social é um recurso para o indivíduo que pertence a uma determinada estrutura. Robert Putnam aplicou o conceito na compreensão da participação e engajamento da sociedade e os seus efeitos nas instituições democráticas e na qualidade do governo em algumas regiões da Itália. Os dois tratam o capital social como um recurso coletivo baseado nas normas e redes de intercâmbio entre os indivíduos.

Já Pierre Bourdieu trata o capital social como a soma dos recursos decorrentes da existência de uma rede de relações de reconhecimento mútuo institucionalizada em campos sociais. Os recursos são empregados pelas pessoas a partir de uma estratégia de progresso dentro da hierarquia social do campo, prática resultante da interação entre o indivíduo e a estrutura. Cada campo social se caracteriza como um espaço onde se manifestam relações de poder, o que significa dizer que os campos sociais se estruturam a partir da distribuição desigual de um quantum social que determina a posição que cada agente específico ocupa em seu interior. P. Bourdieu denomina esse quantum de "capital social". A estrutura do campo 
Redes e capital social: o enfoque da informação para o desenvolvimento local

é composta, desse modo, por dois pólos opostos: o dos dominantes e o dos dominados. Os agentes que ocupam o primeiro pólo são justamente aqueles que possuem um máximo de capital social, enquanto os que se situam no pólo dominado definem-se pela ausência ou pela escassez do capital valorizado no espaço específico do seu campo de pertencimento e, por sua vez, na sociedade como um todo (Bourdieu, 1985). As bases teóricas de explicitação do conceito de capital social mais diretamente orientadas ao campo econômico estão presentes na pesquisa sobre a burguesia francesa (Bourdieu e Saint Martin, 1978). E um extenso e profundo trabalho empírico, os autores desenvolvem uma metodologia para conhecer a origem e o comportamento do patronato francês, analisando desde sua origem familiar, passando pelas escolas e clubes que freqüentam, até as associações das quais fazem parte. Ao evidenciar as relações existentes entre as estratégias econômicas de sobrevivência das empresas e as suas equivalentes de sobrevivência familiar, o papel do sistema de ensino e das redes familiares e empresariais e das redes oriundas das escolas de nível superior, os autores demonstram a importância das diferentes redes nas quais os membros do patronato francês estão inseridos. Elas representam, assim, o seu capital social. Embora não se utilize com freqüência o conceito de rede, fica clara a sua importância para a solidez da análise. No andamento da investigação, surgem outros conceitos de capital associados às redes, como o capital de relações pessoais e o capital de informação, dentre outras formas de capitais associados aos agentes e às estruturas nas quais estão situados.

\section{CAPITAL SOCIAL E DESENVOLVIMENTO}

Existem evidências de que o capital social pode ser usado para promover a redução da pobreza, o desenvolvimento e o bem-estar social, o que aproximaria os interesses da sociologia e da economia nesse campo. Parte do suporte metodológico oferecido pela literatura se origina na análise de redes sociais. Em contrapartida, a literatura econômica sobre o assunto é bastante ampla, especialmente sobre o conceito de capital.

A literatura econômica reconhece diferentes formas de capital, que em comum têm a possibilidade de serem acumulados. Muitas formas de capital possuem, também, características que permitem que sejam valorados e transacionados no mercado, ou seja, o mercado determina o seu preço e a sua disponibilidade, enquanto a teoria do desenvolvimento econômico associa a acumulação de capital ao crescimento. O capital social é uma forma de capital, e, embora sua definição seja alvo de discussão na ciência econômica, algumas características parecem se destacar em alguns estudos, como a não-ocorrência de retornos decrescentes; que o capital social se aprecia com o uso (não se deprecia, portanto); é produzido coletivamente a partir das relações sociais existentes nas comunidades, mas seus benefícios não podem ser antecipadamente mensurados. Embora possua características de bem público, observa-se nele um aspecto único, qual seja, a sua produção é, necessariamente, coletiva. O capital social gera externalidades, mas sua análise deve transcender esse ponto, isto é, o capital social entendido como um conjunto de redes e normas, permitindo a redução dos riscos decorrentes das relações entre desconhecidos e, conseqüentemente, dos custos de transação. No entanto, sua mensuração é problemática e, embora ele possa ser associado ao desenvolvimento, especialmente local, sua promoção não é trivial, ou seja, como ele está incrustado nas redes de relações sociais, não é evidente, do ponto de vista das pesquisas na área de economia, como a sua expansão ou modificação pode afetar o bem-estar de seus componentes.

Além disso, conceitos como "confiança", "comunidade" e "redes" são difíceis de serem operacionalizados e, mais ainda, de serem quantificados e qualificados, pois há um acordo entre os estudiosos do tema, segundo o qual não basta identificar o número de componentes das redes (ligações e nós), mas sim apreender a sua importância para a comunidade. Trata-se de um desafio para os pesquisadores e, principalmente, para aqueles interessados em usar o capital social para promover o desenvolvimento.

Como já foi mencionado, o capital social é multidimensional, o que significa incorporar vários níveis e unidades de análise. Assim, os estudos e pesquisas usam combinações de diferentes metodologias de pesquisa quantitativa e qualitativa, respaldadas pelos arcabouços teóricos próprios aos campos epistemológicos implicados nas análises.

De acordo com Glaeser, Laibson e Sacerdote (2002), as bases teóricas para a mensuração empírica dos impactos do capital social são bastante claras, mas o mesmo não acontece com a identificação dos mecanismos associados à criação do capital social. Parte da dificuldade é atribuída ao fato de que o verdadeiro proprietário do capital social não é o indivíduo, mas a comunidade, por intermédio da rede de relações existentes. Assim, os economistas têm dificuldade em criar um quadro conceitual no qual a comunidade deve ser tratada como uma unidade capaz de tomar decisões.

Muitas críticas foram feitas ao conceito de capital social, assim como à sua utilização indiscriminada, como se fosse um conceito capaz de apontar saídas para todos os males da exclusão social e que permitiria resolver os problemas do baixo nível de desenvolvimento. Se é verdade que 
as redes sociais dificultam o surgimento da figura do "carona" (free rider, aquele indivíduo que se beneficia sem contribuir), dificultando o oportunismo, podem, também, excluir novos participantes, impor normas que prejudiquem grupos específicos dentro de uma comunidade (como, por exemplo, mulheres, praticantes de determinada religião etc.) ou atitudes em relação a outros grupos, como para impedir que outras comunidades tenham acesso a determinados serviços públicos. Portanto, é importante destacar que nem toda forma de capital social é positiva, e que este pode ser usado negativamente contra os que estão fora de uma determinada rede, ou ainda gerar grupos corruptos e sistemas autoritários. Outra crítica é que podem ocorrer situações não estimuladoras de iniciativas individuais e de restrições à liberdade individual.

\section{REDES, CAPITAL SOCIAL E A MEDIAÇÃO ENTRE A SOCIEDADE E O ESTADO}

Várias pesquisas nas ciências sociais que utilizam os conceitos e as metodologias de análise de redes procuram identificar a organização das comunidades a partir de problemas específicos, associados, em sua maioria, à ineficácia ou mesmo, à total ausência do Estado. Conforme já exposto, os fluxos de informação e o conhecimento produzido pelos laços existentes entre os membros da comunidade dependem de características culturais, sociais, econômicas e políticas, que também determinam a participação de cada um e as sanções para os não-participantes. Em suma, orientam os valores e normas de cada rede, supondo que em cada comunidade existam, superpostas, várias delas, muitas criadas ad hoc. Nas ciências sociais, as redes designam normalmente os movimentos fracamente institucionalizados, e sua dinâmica está voltada para a perpetuação, consolidação e desenvolvimento das atividades dos indivíduos. Muitas redes se iniciam a partir da tomada de consciência sobre algum problema vivenciado por uma ou mais comunidades, ou a partir de situações de mobilização mais amplas. Criam-se, nas redes, formas institucionais próprias associadas aos direitos, responsabilidades e tomadas de decisão. A posição de cada indivíduo na rede depende do capital social e informacional que consiga agregar para si próprio e para o conjunto. A margem de decisão de um indivíduo inserido em uma rede social está sujeita à distribuição de poder, à estrutura de interdependência e de tensões no interior do grupo. É a ocupação de determinadas posições na rede da comunidade, de especial acesso a informações, que determina o sucesso das ações dos indivíduos e seus grupos.

Existem muitas formas de emprego da idéia de redes nas ciências sociais, desde tomá-la como uma metáfora que orienta a visão de que entidades, indivíduos ou mesmo idéias estão de alguma forma conectados entre si, passando pelo seu emprego normativo, determinando certas configurações de um dado conjunto de entidades de maneira a alcançar certos objetivos, ou, mais recentemente, como método de análise das redes sociais. Nesse uso teórico-metodológico mais recente, trata-se de considerar as redes não apenas como metáfora da estruturação das entidades na sociedade, mas também como método para a descrição e a análise dos padrões de relações nelas presentes (Marques, 2000).

Nos estudos da informação ressaltam-se as vantagens do emprego da metodologia de análise de redes sociais para investigar as formas de racionalidade presentes em entidades, indivíduos e grupos da sociedade na sua interação com o Estado, no que tange aos processos de intervenção social para a formulação e deliberação de políticas públicas. Um dos campos de tensão política e informacional que têm sindo estudados com o auxílio dessa metodologia é o das práticas de intervenção social em saúde. A análise de redes, contemplada com teorias e conceitos das ciências sociais e da informação, permite traçar os fluxos de informações e as construções cognitivas e simbólicas de atores posicionados em espaços sociais diferenciados (do Estado, da academia, do empresariado, da mídia, das associações e entidades civis, dos grupos e lideranças comunitárias) para o direcionamento e deliberação de questões referentes às condições de saúde da população e à implantação de políticas (Marteleto, 2001).

Evidencia-se, por outro lado, que os indivíduos organizam suas ações nos espaços políticos em função de socializações e mobilizações suscitados pelo próprio desenvolvimento de suas redes. As relações com outras esferas, além do espaço comunitário, são influenciadas pela existência das redes sociais, que operam como mediadoras entre a sociedade e o Estado. No plano metodológico, evidenciamse as relações entre o nível micro das relações sociais - foco essencial da análise de redes - e o nível macro das estruturas sociais. Ou seja, trata-se de uma maneira de abordar as questões e práticas sociais, dentre elas as informacionais, comunicacionais e cognitivas, com foco na sua expressão e ocorrência local e interativa, sem que se percam de vista os determinantes estruturais da sociedade, da economia e do Estado.

Pode-se perceber, nas ações de intervenção social em saúde, uma "polifonia discursiva" de atores, linguagens e visões que procuram, cada qual, fazer valer a sua lógica de produção de conhecimentos e informações a respeito das questões em pauta no cenário da precariedade das condições de vida e de saúde da população. Nesse contexto e como já tratado neste artigo na definição de capital 
Redes e capital social: o enfoque da informação para o desenvolvimento local

social, operam três redes que ampliam o alcance das ações da comunidade: os laços entre os membros da comunidade, isto é, entre pares ou iguais (capital social de ligação); entre os membros da comunidade e representantes de organizações não-governamentais, que ampliam os laços da comunidade (capital social de ponte); entre as lideranças sociais e comunitárias e os representantes das instituições acadêmicas, que abrem os contatos dos agentes das redes locais com representantes que têm autoridade e ligação com instituições públicas (capital social de conexão).

Embora não se associe diretamente, nesse caso, a existência das redes e do capital social que representam ao aumento do bem-estar, há uma preocupação com seu impacto na construção da cidadania. $O$ conhecimento construído pela comunidade em um contexto de mudanças, no qual os papéis do Estado e do mercado vêm se alterando, ressalta a importância da organização de redes de contato que mobilizam recursos materiais e simbólicos para a transformação social, promovendo novas e complementares formas de apropriação e produção de conhecimentos e, também, da transferência e gestão de informações, fora da regulação estatal (Marteleto e Ribeiro, 2001).

\section{CAPITAL SOCIAL E REDES DE EMPRESAS NOS ARRANJOS PRODUTIVOS LOCAIS}

A constituição de redes e o uso da informação na geração do conhecimento para o desenvolvimento local também constituem objetos de estudo importantes na análise das relações entre atores econômicos, tais como as existentes entre as empresas e outras organizações (governo, universidades, institutos de pesquisa etc.). A análise de redes sociais pode ser usada, também, para se compreender a relação existente entre firmas e empresários nos denominados clusters ou arranjos produtivos locais.

Na literatura sobre o assunto, "os aglomerados de empresas em uma região em torno de uma área de negócio” vêm recebendo, entre outras, as seguintes denominações: "distrito industrial", "sistemas produtivos locais", "arranjos produtivos locais" e "clusters". Embora haja distinções entre eles e entre os diversos autores para um mesmo termo, todos enfatizam a existência de mecanismos sociais de confiança e cooperação entre os agentes envolvidos e o fato de as empresas se organizarem em rede. Nesse tópico, estará se utilizando o termo cluster como sendo o conjunto de organizações e instituições concentradas geograficamente em torno de um ou mais setores industriais. Eles abrangem uma rede de indústrias, em sua maioria pequenas e médias, com tecnologias de produção flexíveis, sendo, portanto, capazes de responder rapidamente às mudanças nas condições de mercado. Dentro de sua área de influência, existe forte interação entre as empresas e as instituições de apoio, financiamento e pesquisa, e de todas com o meio sociocultural local, por meio de relações mercantis e informais que geram externalidades positivas para o conjunto de agentes econômicos envolvidos.

Recentemente, as teorias de desenvolvimento regional sofreram grandes transformações, em especial pelo surgimento de regiões dinâmicas portadoras de um novo paradigma industrial no qual os ativos intangíveis passaram a ser mais importantes que os tangíveis, e a flexibilidade e capacidade de se antecipar a mudanças no ambiente passaram a ser características fundamentais das empresas. Mais do que isso, a análise se desloca da empresa individual para o ambiente que a envolve, especialmente as redes de relacionamento existentes entre os atores. Assim, a análise dos aglomerados de empresas - clusters - passa a incluir as redes existentes, que podem ser vistas de duas óticas complementares: a dos indivíduos envolvidos com as empresas (empresários, gerentes e empregados em geral), na qual os laços de amizade e conhecimento são relevantes para os contatos profissionais, e das empresas e organizações (fornecedores de todos os tipos, concorrentes, universidades e associações etc.), na qual os laços econômicos são os objetos da investigação. Estudos em vários países demonstram que os sistemas produtivos nos quais as redes de conhecimento funcionam para diminuir o custo de obtenção de informação e aumentar a criação de conhecimento são mais flexíveis e dinâmicos que aqueles nos quais as redes existentes não funcionam dessa forma.

Em uma análise sobre as idéias básicas da nova sociologia econômica, Richter (2001) destaca que as suas abordagens teóricas são, fundamentalmente, ecléticas e pluralistas. Destaca algumas contribuições fundamentais, como o conceito de "embeddedness" (ancoramento, encrustramento, não há uma boa tradução para o termo), tomado de Karl Polanyi e ampliado por Granoveter (1985) para representar o fato de que toda a ação econômica ocorre no interior das redes de relações sociais que definem a estrutura social. Acrescenta, a essa contribuição, a de DiMaggio (1990), que vai além afirmando que a ação econômica está ancorada (embedded) tanto na estrutura social, quanto na cultura. Richter (2001) apresenta também algumas áreas de pesquisa no campo da sociologia econômica, das quais três são relevantes para esse trabalho. A primeira é a sociologia da firma e da organização industrial, a segunda é a crítica à economia institucional, em especial os custos de transação, e a terceira, a sociologia das regiões industrias.

Nessa última área, destaca-se o trabalho de Saxenian (1996), que compara o desempenho de dois clusters da área de eletrônica, destacando os fatores responsáveis pelo sucesso do Vale do Silício, não presentes na região estagnada da região 
da Rodovia 128 (Estado de Massachusetts), atribuindo grande parte das diferenças de comportamento à formação de redes. Essas envolviam tanto as pessoas para a troca de informações e conhecimentos, quanto, mais tarde, as empresas que usavam mecanismos de subcontratação e divisão do trabalho (ao contrário da verticalização das empresas da Rodovia 128). Destacou, além dessas características, o incentivo à experimentação e ao empreendedorismo, em uma área de tecnologias novas e complexas (portanto em um ambiente de incerteza e risco), bem como a troca de informações e conhecimento entre as pessoas e empresas e as práticas de trabalho colaborativas. Nas empresas da região, as estruturas internas eram bastante horizontais e porosas, entre as diversas áreas da empresa e entre as empresas.

Essa abordagem deixa claro que, para se entender a relevância dos clusters de empresas (ou arranjos produtivos) para o processo de desenvolvimento e a importância da análise do processo de criação de conhecimento e de aprendizado em seu interior, é necessário se investigarem os processos de geração do conhecimento não só nas empresas, mas também nos processos interativos entre as empresas e instituições, ou seja, o quão inovadoras são as empresas localizadas em determinado cluster e qual a importância de cada ator, sejam eles empresas e organizações, sejam eles os indivíduos a elas associados.

A importância da confiança na reprodução da colaboração entre os agentes econômicos dentro dos clusters deve ser enfatizada. As inter-relações das empresas em uma rede de produção estão baseadas nas relações sociais e culturais, tais como de parentesco, religião, etnia, educação e condições históricas, políticas ou sindicais, que formam a base da comunidade local. Tal confiança é adquirida, após um período de tempo, por meio de contínuas contratações e recontratações, mediante acordos informais, dentre outras coisas, e é exatamente a presença desse ambiente sociocultural, institucional e econômico que forma a base para a existência de externalidades econômicas, economias de escala, eficiência, economias de aglomeração, capacidade inovadora, criatividade industrial descentralizada, potencial para o desenvolvimento endógeno no nível regional e local, como também especialização flexível.

Estudos sobre cluster utilizando-se da metodologia de análise de redes sociais têm sido realizados no período recente, embora ainda não se possa dizer que configurem uma área de produção significativa. $\mathrm{O}$ capital social contido nas redes de relações dos indivíduos que atuam no cluster (ou a falta dele) pode ser bem compreendido e visualizado com o uso dessa metodologia. Em um estudo realizado para a Universidad de Aguascalientes, do México, sobre o cluster de roupas na cidade de Villa Hidalgo, norte do
Estado de Jalisco, foi aplicada essa metodologia (Mácias, 2002). A pesquisa ainda não foi concluída, mas os resultados iniciais compararam as redes pessoais (laços familiares, de amizade, conhecimento, de ensino entre os empresários existentes e os novos empresários etc.) e as redes econômicas (subcontratação e cooperação), mostrando evidências no sentido das forças dos laços fracos estudadas por Granovetter (1973), isto é, os laços de conhecimento seriam mais relevantes que os familiares para a existência de relações econômicas entre as empresas, mas não apresentando resultados significativos para a influência das relações de confiança para a configuração produtiva do cluster. O capital social existente, representado por uma densa rede de relações familiares e de amizade, não está se traduzindo em oportunidades de negócios. $\mathrm{O}$ estudo aponta para a necessidade de se aprofundarem esses pontos.

\section{CONCLUSÕES}

A análise de rede é uma alternativa metodológica que permite uma interlocução entre as ciências sociais e a ciência da informação, especialmente quando se leva em conta o conceito de capital social e o interesse que vem despertando nessas áreas. O interesse é decorrente de uma nova visão sobre o desenvolvimento, que reforça o papel das organizações e redes locais constituídas independentemente do Estado. A compreensão dos fluxos de informação, de conhecimento e de poder que percorrem as redes, e o papel dos diferentes atores envolvidos pode permitir a elaboração de políticas públicas de inclusão e geração de bem-estar, que vão do acesso a serviços públicos de saúde e educação ao crédito para funcionamento dos negócios.

$\mathrm{O}$ acesso à informação, especialmente aquele existente fora do grupo, e sua importância para o desenvolvimento, seja das comunidades, seja das empresas, é o elemento-chave a ser investigado. Da mesma forma, as ações políticas não podem ignorar as informações que os próprios grupos elaboram a partir de seus universos locais de vivência, interação e trabalho.

Deve-se tomar cuidado, no entanto, com as generalizações fáceis e com a visão ingênua das redes sociais e do capital social. Conforme assinalado por Degenne e Forsé (1994), tudo pode ser reduzido à rede. Precaução semelhante deve ser tomada em relação ao conceito de capital social. No entanto, inegavelmente, as possibilidades de pesquisa tendo por base a metodologia de redes e o conceito de capital social são desafiadoras. No caso específico dos arranjos produtivos locais e do potencial das redes sociais locais para a formulação de informações capazes de orientar a formulação de políticas públicas no Brasil, há um imenso vazio a ser ocupado por pesquisas com essas abordagens, teorias, conceitos e metodologias. 


\section{Redes e capital social: o enfoque da informação para o desenvolvimento local}

Artigo recebido em 02-09-2004 e aceito para publicação em 29-03-2005.

\section{REFERÊNCIAS}

BOURDIEU, Pierre. The forms of capital. In: RICHARDSON, J. (Comp.). Handbook of theory and research for the sociology of education. New York : Greenwood, 1985. ; SAINT-MARTIN, Monique de. Le patronat. Actes de la Recherche en Science Sociales, Paris, n. 20/21, p. 3-82, 1978.

DEGENNE, Alain ; FORSÉ, Michel. Les réseaux sociaux: une analyse structurale en sociologie. Paris : Armand Colin, 1994.

DiMAGGIO, Paul. Cultural aspects of economic action and organization. In: FRIEDLAND, R.; ROBERTSON, A. F. (Ed.). Beyond the market place. New York : Aldine de Gruyter, 1990. p. 113-136.

DURSTON, John. El capital social campesino en la gestión del desarrollo rural: díadas, equipos, puentes y escaleras. Santiago de Chile : Comisión Económica para América Latina y el Caribe, 2002.

ELIAS, Norbert. A sociedade dos indivíduos. Rio de Janeiro : Zahar, 1994.

GLAESER, Edward; LAIBSON, David; SACERDOTE, Bruce. An economic approach to social capital. Economic Journal, Oxford, v. 112, n. 483, p. 437-458, Nov. 2002.

GRANOVETTER, Mark. Economic action and social structure: the problem of embeddedness. American Journal of Sociology, Chicago, v. 91, n. 3, Nov. 1985.

. The strength of weak ties. American Journal of Sociology, Chicago, v. 78, n. 6, p. 1360-1380, May 1973
HANNEMAN, Robert A. Introducción a los métodos del análisis de redes sociales. Disponível em: < http://revista-redes.rediris.es/webredes/>. Acesso em: 03 abr. 2004.

MACÍAS, Alejandro García. Redes sociales y "clusters" empresariales. Revista Hispana para el Análisis de Redes Sociais, v. 1, n. 6, enero 2002. Disponível em: <http://revista-redes.rediris.es/html-vol1/vol1_6.htm>. Acesso em: 15 jun. 2004.

MARQUES, Eduardo César. Estado e redes sociais: permeabilidade e coesão nas políticas urbanas no Rio de Janeiro. São Paulo : FAPESP/ Revan, 2000

MARTELETO, Regina Maria. Análise das redes sociais: aplicação nos estudos de transferência da informação. Ciência da Informação, Brasília, v. 30, n. 1, p.71-81, jan./abr. 2001.

; RIBEIRO, Leila Beatriz. Informação e construção do conhecimento para a cidadania no terceiro setor. Revista Informação e Sociedade, João Pessoa, v. 11, n.1, 2001. Disponível em: <http://www. informacaoesociedade.ufpb.br/1110103.html>. Acesso em: 05 jul. 2004.

NATIONAL ECONOMIC AND SOCIAL FORUM. The policy implications of social capital. Dublin, 2003. 157 p. (Forum report, n. 28).

RICHTER, Rudolf. New economic sociology and new institucional economics. In: ANNUAL CONFERENCE OF THE INTERNATIONAL SOCIETY FOR INSTITUCIONAL ECONOMICS, 5, 2001, Berkeley. Proceedings ... Berkeley, 2001. [S. 1., 2001?]. 39 p. Disponível em: <http:// www.isnie.org/ISNIE01/Papers01/richter.pdf>. Acesso em: 05 jul. 2004.

SAXENIAN, Annalee. Regional advantage: culture and competition in silicon valley and route 128. Cambridge, Massachusetts : Harvard University, 1996.

WATTS, Duncan J. Small worlds: the dynamics of networks between order and randomness. New Jersey : Princeton University, 1999. 264 p. 